\title{
Comparison between robotic-assisted and laparoscopic sphincter-preserving operations for ultra-low rectal cancer: a single institutional retrospective study
}

\section{Tadahiro Kojima}

Division of Colon and Rectal Surgery, Shizuoka Cancer Center Hospital Hitoshi Hino ( $\nabla$ h.hino@scchr.jp )

Division of Colon and Rectal Surgery, Shizuoka Cancer Center Hospital

\section{Akio Shiomi}

Division of Colon and Rectal Surgery, Shizuoka Cancer Center Hospital Hiroyasu Kagawa

Division of Colon and Rectal Surgery, Shizuoka Cancer Center Hospital

\section{Yusuke Yamaoka}

Division of Colon and Rectal Surgery, Shizuoka Cancer Center Hospital

\section{Shoichi Manabe}

Division of Colon and Rectal Surgery, Shizuoka Cancer Center Hospital

\section{Shunichiro Kato}

Division of Colon and Rectal Surgery, Shizuoka Cancer Center Hospital

\section{Marie Hanaoka}

Division of Colon and Rectal Surgery, Shizuoka Cancer Center Hospital

\section{Research article}

Keywords: Sphincter-preserving operations, Laparoscopic surgery, Robotic surgery, Rectal cancer, Low anterior resection, Intersphincteric resection

Posted Date: August 12th, 2021

DOl: https://doi.org/10.21203/rs.3.rs-799218/v1

License: (c) (1) This work is licensed under a Creative Commons Attribution 4.0 International License. Read Full License 
Version of Record: A version of this preprint was published at Annals of Gastroenterological Surgery on March 15th, 2022. See the published version at https://doi.org/10.1002/ags3.12564. 


\section{Abstract \\ Background}

Sphincter-preserving operations for ultra-low rectal cancer include low anterior resection and intersphincteric resection. In low anterior resection, the distal rectum is divided by a transabdominal approach, which is technically demanding. In intersphincteric resection, a perineal approach is performed. We aimed to evaluate whether robotic-assisted surgery is technically superior to laparoscopic surgery for ultra-low rectal cancer. The frequency of conducting low anterior resection by a specific procedure can indicate the technical superiority of that procedure for ultra-low rectal cancer. Thus, we compared the frequency of low anterior resection between robotic-assisted and laparoscopic surgery in cases of sphincter-preserving operations.

\section{Methods}

We investigated 183 patients who underwent sphincter-preserving robotic-assisted or laparoscopic surgery for ultra-low rectal cancer (lower border within $5 \mathrm{~cm}$ of the anal verge) between April 2010 and March 2020. The frequency of low anterior resection was compared between laparoscopic and roboticassisted surgeries. The clinicopathological factors associated with an increase in performing low anterior resection were analyzed by multivariate analyses.

\section{Results}

Overall, 41 (22.4\%) and 142 (77.6\%) patients underwent laparoscopic and robotic-assisted surgery, respectively. Patient characteristics were similar between the groups. Low anterior resection was performed significantly more frequently in robotic-assisted surgery $(67.6 \%)$ than in laparoscopic surgery $(48.8 \%)(p=0.04)$. Multivariate analyses showed that tumor distance from the anal verge $(p<0.01)$ and robotic-assisted surgery $(p=0.02)$ were significantly associated with an increase in the performance of low anterior resection. The rate of postoperative complications or pathological results was similar between the groups.

\section{Conclusions}

Compared with laparoscopic surgery, robotic-assisted surgery significantly increased the frequency of low anterior resection in sphincter-preserving operations for ultra-low rectal cancer. Robotic-assisted surgery has technical superiority over laparoscopic surgery for ultra-low rectal cancer treatment.

\section{Background}


Surgical outcomes of robotic-assisted surgery (RS) for rectal cancer have recently been reported [1-3]. Several studies have shown excellent outcomes with RS in terms of urinary function, sexual function, defecatory function, and local recurrence rate for rectal cancer compared to those achieved by laparoscopic surgery (LS) or open surgery (OS) [4-9].

To date, differences in the types of RS and LS for low rectal cancer have not been fully investigated. The advanced technology of RS allows sphincter-preserving operations (SPOs) to be performed more often than LS or OS $[10,11]$. Further, RS enables patients with low rectal cancer to avoid abdominoperineal resection (APR) and the creation of a permanent stoma, suggesting that RS would be technically superior. Nevertheless, the indications for SPOs are determined not only by technical factors but also by anorectal function and lifestyle. SPOs markedly influence postoperative defecatory function [12]. Consequently, preoperative anorectal functions and the patient's acceptance of postoperative bowel dysfunction must always be considered when contemplating an SPO. Therefore, to evaluate the technical superiority of RS for rectal cancer in terms of selecting the type of operation, investigating only the frequency of SPOs would be insufficient.

For a more detailed investigation of the technical superiority of RS with regard to the operation type, we focused on two SPOs, low anterior resection (LAR) and intersphincteric resection (ISR), performed for ultra-low rectal cancer. [13]. Generally, LAR is performed when the distal rectum can be divided using linear staplers via a transabdominal approach, and ISR is performed when this is not possible. Dividing the distal rectum via the transabdominal approach is technically demanding, and the type of SPO that can be performed depends mainly on technical factors. Therefore, the frequency of conducting LAR by a specific procedure can indicate the technical superiority of that procedure for ultra-low rectal cancer. Thus, in this study, we compared the frequency of LAR between RS and LS in patients who underwent SPOs for ultra-low rectal cancer to evaluate whether RS was technically superior to LS.

\section{Methods}

\section{Patient Selection}

Data were collected from the institutional database at Shizuoka Cancer Center and were analyzed retrospectively. Between April 2010 and March 2020, 287 patients with primary ultra-low rectal adenocarcinoma (lower edge of the tumor within $5 \mathrm{~cm}$ from the anal verge [AV]) underwent roboticassisted or laparoscopic SPO with curative intent. SPOs included LAR and ISR, and all patients underwent transabdominal total mesorectal excision (TME) [14]. No patients underwent transanal TME (TaTME). During LAR, both TME and division of the distal rectum using a linear stapler were performed via a transabdominal approach. The coloanal anastomosis was performed using the double-stapling technique. ISR was defined as a surgical procedure that included both transabdominal and transanal approaches. In ISR, TME was performed using the transabdominal approach, followed by transanal resection. This involved surgical dissection of the intersphincteric space and en bloc resection of the rectum, together with the internal anal sphincter within the anatomical anal duct. After removal of the 
specimen, a coloanal anastomosis was performed using transanal manual suturing in all patients $[15$, 16]. Patients in whom the intersphincteric space could be entered and in whom partial excision of the internal anal sphincter was performed via the transabdominal approach were included in the LAR group, as previously described [17].

We excluded patients with tumors that extended into the anal canal, those who received preoperative treatment, such as chemotherapy and/or radiotherapy, those with multi-visceral resection, and those with a history of colectomy other than appendectomy (Fig. 1). Consequently, 183 patients were enrolled in this study.

Preoperative assessment included digital rectal examination, colonoscopy, computed tomography, contrast enema, and magnetic resonance imaging. If necessary, positron-emission tomographycomputed tomography was performed. Tumor staging was performed using the tumor node metastasis classification [18]. The indications for lateral lymph node dissection (LLD) were low rectal adenocarcinoma with cT3-4 or cT1-2 with metastasis to the lateral lymph nodes $[19,20]$. However, LLD was not performed if the patients without lateral lymph node metastasis on preoperative images were 75 years or older, had severe comorbidities, or received preoperative chemoradiation [19]. Consistent with a previous report, we regarded lateral lymph nodes as regional lymph nodes [21].

At our institution, RS was introduced in December 2011. Until March 2018, the national public health insurance in Japan did not cover RS for rectal cancer. Thus, RS was an expensive procedure. The selection of RS, LS, or OS was based on the patient's preference and informed consent. Since April 2018, RS is covered by the national public health insurance. We, therefore, performed RS for most patients.

The study was approved by the institutional review board of Shizuoka Cancer Center (Approval Code: J2020-37-2020-1-3).

\section{Indications for SPO}

SPO was indicated only for patients with the following characteristics: a clear resection margin, acceptable postoperative anal function, and absence of invasion into the levator ani muscles and external anal sphincter. The standard operative rule was total TME with autonomic nerve preservation [14]. Japanese D2 or D3 lymph node dissection was performed $[12,15]$. LAR was indicated for patients in whom the transabdominal approach could divide the distal rectum using linear staplers. ISR was performed when the distal rectum could not be divided via the transabdominal approach, either because of technical difficulties or to ensure a sufficient distal resection margin. ISR was excluded for patients with poorly differentiated adenocarcinoma or with decreased anal sphincter tonus. APR was performed when (1) the tumor invaded the external anal sphincter or levator ani muscles, (2) the tumor was the diffuse infiltrative spreading type based on macroscopic appearance, (3) fecal continence was impaired preoperatively, or (4) patients could not tolerate postoperative defecatory dysfunction. All treatment strategies were approved in a multidisciplinary team conference.

\section{Surgical Procedure}


The institutional standard surgical procedure has been described elsewhere [22-24]. The surgical procedure was almost the same in both LAR and ISR up to dividing the rectum. In brief, the inferior mesenteric artery and vein ligations and colon mobilization were performed via a medial-to-lateral approach. The rectum was mobilized down to the pelvic floor as for TME. During LAR, the distal rectum was divided using linear staplers via the transabdominal approach. In RS, robotic-assisted or a conventional laparoscopic linear stapler was used. In LS, only a conventional laparoscopic linear stapler was used. The specimen was extracted through a mini-laparotomy at the umbilical site. The standard double-stapling technique was utilized for end-to-end anastomosis. A diverting stoma was constructed if necessary. In patients who underwent ISR, intersphincteric dissection and specimen extraction were performed via the transanal approach [24] The coloanal anastomosis was hand-sewn. A diverting stoma was constructed in all patients who underwent ISR. During the transanal part of the surgery, the surgical procedure was the same in both RS and LS [20].

\section{Outcome Variables}

We collected data on patient characteristics as well as perioperative outcomes, including the frequency of LAR, postoperative complications, and pathological results. Postoperative complications within 30 days were categorized according to the Clavien-Dindo classification system [25]. The association between clinicopathological factors and SPO type was analyzed. The radicality of each surgical procedure was defined as R0 (macroscopic complete resection with no microscopic residual tumor), R1 (macroscopic complete resection with microscopic residual tumor at the resection margin), or R2 (macroscopic residual tumor).

\section{Statistical Analyses}

Parametric variables are expressed as median values. The Fisher's exact test, the chi-squared test, and the Mann-Whitney U test were used, as appropriate, to assess the significance of between-group differences. Univariate and multivariate logistic regression analyses were performed to identify factors associated with the performance of LAR. A p-value of $<0.05$ was considered significant. All statistical analyses were performed using R software version 3.5.2 (The R Foundation for Statistical Computing, Vienna, Austria).

\section{Results}

A total of 183 consecutive patients who underwent SPOs for ultra-low rectal cancer were analyzed. The characteristics of the 41 (22.4\%) patients who underwent LS and $142(77.6 \%)$ patients who underwent RS are summarized in Table 1. Although the clinical stage in the RS group tended to be more advanced than that in the LS group, the difference was not statistically significant. 
Table 1

Patient characteristics

\begin{tabular}{|c|c|c|c|}
\hline & $L S$ & $R S$ & \\
\hline & $(n=41)$ & $(n=142)$ & $p$ \\
\hline Age (years) & $65(29-83)$ & $64(29-84)$ & 0.61 \\
\hline Sex & & & 0.19 \\
\hline Male & $24(58.5 \%)$ & 100 (70.4\%) & \\
\hline Female & $17(41.5 \%)$ & $42(29.6 \%)$ & \\
\hline \multirow[t]{2}{*}{ BMI $\left(\mathrm{kg} / \mathrm{m}^{2}\right)$} & 23.0 & 23.1 & 0.74 \\
\hline & $(12.8-37.6)$ & $(15.7-32.5)$ & \\
\hline ASA-PS & & & 0.12 \\
\hline 1 & $11(26.8 \%)$ & $33(23.2 \%)$ & \\
\hline 2 & $26(63.4 \%)$ & $105(73.9 \%)$ & \\
\hline 3 & $4(9.8 \%)$ & $4(2.8 \%)$ & \\
\hline Tumor distance from the AV $(\mathrm{cm})$ & $5.0(3.0-5.0)$ & $5.0(2.0-5.0)$ & 0.38 \\
\hline Tumor size $(\mathrm{mm})$ & $33(2-122)$ & $36(2-121)$ & 0.85 \\
\hline Clinical T stage & & & 0.44 \\
\hline T1 & $15(36.6 \%)$ & $41(28.9 \%)$ & \\
\hline $\mathrm{T} 2$ & $9(22.0 \%)$ & $25(17.6 \%)$ & \\
\hline T3 & $15(36.6 \%)$ & $71(50.0 \%)$ & \\
\hline T4 & $2(4.9 \%)$ & $5(3.5 \%)$ & \\
\hline Clinical N stage & & & 0.19 \\
\hline No & $31(75.6 \%)$ & $84(59.2 \%)$ & \\
\hline N1 & $7(17.1 \%)$ & 37 (26.1\%) & \\
\hline N2 & $3(7.3 \%)$ & $21(14.8 \%)$ & \\
\hline Clinical stage & & & 0.18 \\
\hline I & 21 (51.2\%) & 55 (38.7\%) & \\
\hline
\end{tabular}

Values are expressed as the number (percentage) or median value (range).

LS: laparoscopic surgery, RS: robotic-assisted surgery, BMI: body mass index, ASA-PS: American Society of Anesthesiologists-Physical Status, AV: anal verge 


\begin{tabular}{|lcc|}
\hline \multicolumn{1}{|l|}{ LS } & \multicolumn{1}{l|}{ RS } \\
\hline II & $10(24.4 \%)$ & $28(19.7 \%)$ \\
\hline III & $10(24.4 \%)$ & $51(35.9 \%)$ \\
\hline IV & $0(0.0 \%)$ & $8(5.6 \%)$ \\
\hline Values are expressed as the number (percentage) or median value (range). \\
\hline \multicolumn{2}{|l}{ LS: laparoscopic surgery, RS: robotic-assisted surgery, BMl: body mass index, ASA-PS: American } \\
\hline
\end{tabular}

Table 2 summarizes the perioperative outcomes. Compared to the LS group, LLD was performed significantly more frequently in the RS group. Operative times were significantly longer in the RS group than in the LS group. However, when the patients who underwent LLD were excluded, operative times in the RS group tended to be shorter than those in the LS group (Supplementary Table 1). The frequency of LAR was significantly higher, blood loss was significantly less, and the length of postoperative hospital stay was significantly shorter in the RS group than in the LS group.

Table 2

Perioperative outcomes

\begin{tabular}{|c|c|c|c|}
\hline & $L S$ & $R S$ & \\
\hline & $(n=41)$ & $(n=142)$ & $p$ \\
\hline Operative time (minutes) & $305(153-528)$ & $322(138-625)$ & 0.02 \\
\hline Blood loss (mL) & $29(0-385)$ & $13(0-215)$ & 0.02 \\
\hline Type of operation & & & 0.04 \\
\hline ISR & $21(51.2 \%)$ & $46(32.4 \%)$ & \\
\hline LAR & $20(48.8 \%)$ & $96(67.6 \%)$ & \\
\hline Lateral lymph node dissection & $8(19.5 \%)$ & $70(49.3 \%)$ & $<0.01$ \\
\hline Diverting stoma & $25(61.0 \%)$ & $85(59.9 \%)$ & 1.00 \\
\hline Conversion & $0(0.0 \%)$ & $0(0.0 \%)$ & 1.00 \\
\hline Length of postoperative hospital stay (days) & $8(6-28)$ & $7(6-22)$ & 0.01 \\
\hline \multicolumn{4}{|c|}{ Values are expressed as the number (percentage) or median value (range). } \\
\hline \multicolumn{4}{|c|}{$\begin{array}{l}\text { LS: laparoscopic surgery, RS: robotic-assisted surgery, ISR: intersphincteric resection, LAR: low } \\
\text { anterior resection }\end{array}$} \\
\hline
\end{tabular}

The associations between clinicopathological factors and the type of SPO are shown in Table 3. Univariate analyses indicated that tumor distance from the AV and RS were significantly associated with 
an increase in the frequency of LAR for ultra-low rectal cancer. Multivariate analyses revealed that tumor distance from the AV and RS was significantly associated with an increased LAR frequency. 
Table 3

Univariate and multivariate analyses of factors linked to LAR performance frequency

\begin{tabular}{|c|c|c|c|c|c|c|c|c|}
\hline & \multirow{2}{*}{$\begin{array}{l}\text { ISR } \\
(n=67)\end{array}$} & \multirow{2}{*}{$\begin{array}{l}L A R \\
\left(\begin{array}{l}n= \\
116)\end{array}\right.\end{array}$} & \multicolumn{3}{|c|}{ Univariate } & \multicolumn{3}{|c|}{ Multivariate } \\
\hline & & & $\begin{array}{l}\text { Odds } \\
\text { ratio }\end{array}$ & $95 \% \mathrm{Cl}$ & $p$ & $\begin{array}{l}\text { Odds } \\
\text { ratio }\end{array}$ & $\begin{array}{l}95 \% \\
\mathrm{Cl}\end{array}$ & $p$ \\
\hline Age (years) & $\begin{array}{l}63 \\
(29- \\
79)\end{array}$ & $\begin{array}{l}65 \\
(29- \\
84)\end{array}$ & 1.01 & $\begin{array}{l}0.98- \\
1.04\end{array}$ & 0.46 & 1.01 & $\begin{array}{l}0.98- \\
1.05\end{array}$ & 0.54 \\
\hline \multicolumn{3}{|l|}{ Sex } & 0.96 & $\begin{array}{l}0.50- \\
1.82\end{array}$ & 0.90 & 1.03 & $\begin{array}{l}0.46- \\
2.33\end{array}$ & 0.94 \\
\hline Male & $\begin{array}{l}45 \\
(36.3 \%)\end{array}$ & $\begin{array}{l}79 \\
(63.7 \%)\end{array}$ & & & & & & \\
\hline Female & $\begin{array}{l}22 \\
(37.3 \%)\end{array}$ & $\begin{array}{l}37 \\
(62.7 \%)\end{array}$ & & & & & & \\
\hline \multirow[t]{2}{*}{$\mathrm{BMI}\left(\mathrm{kg} / \mathrm{m}^{2}\right)$} & & & \multirow[t]{2}{*}{0.99} & \multirow{2}{*}{$\begin{array}{l}0.91- \\
1.07\end{array}$} & \multirow[t]{2}{*}{0.76} & \multirow[t]{2}{*}{1.03} & \multirow{2}{*}{$\begin{array}{l}0.93- \\
1.14\end{array}$} & \multirow[t]{2}{*}{$0.5 \varepsilon$} \\
\hline & $\begin{array}{l}(12.8- \\
32.3)\end{array}$ & $\begin{array}{l}(15.7- \\
37.6)\end{array}$ & & & & & & \\
\hline \multirow{2}{*}{$\begin{array}{l}\text { Tumor distance from } \\
\text { the AV }(\mathrm{cm})\end{array}$} & 4.0 & 5.0 & \multirow[t]{2}{*}{3.40} & \multirow{2}{*}{$\begin{array}{l}2.06- \\
5.61\end{array}$} & \multirow{2}{*}{$\begin{array}{l}<.01 \\
0.01\end{array}$} & \multirow[t]{2}{*}{3.52} & \multirow{2}{*}{$\begin{array}{l}1.93- \\
6.40\end{array}$} & \multirow{2}{*}{$<$} \\
\hline & $\begin{array}{l}(2.0- \\
5.0)\end{array}$ & $\begin{array}{l}(3.0- \\
5.0)\end{array}$ & & & & & & \\
\hline \multirow[t]{2}{*}{ Tumor size $(\mathrm{mm})$} & 33 & 38 & \multirow[t]{2}{*}{1.01} & \multirow{2}{*}{$\begin{array}{l}0.99- \\
1.02\end{array}$} & \multirow[t]{2}{*}{0.20} & \multirow[t]{2}{*}{1.01} & \multirow{2}{*}{$\begin{array}{l}0.99- \\
1.03\end{array}$} & \multirow[t]{2}{*}{$0.4 \varepsilon$} \\
\hline & $\begin{array}{l}(2- \\
121)\end{array}$ & $\begin{array}{l}(2- \\
122)\end{array}$ & & & & & & \\
\hline \multicolumn{3}{|l|}{ Clinical T stage } & 1.33 & $\begin{array}{l}0.73- \\
2.44\end{array}$ & 0.35 & 0.99 & $\begin{array}{l}0.39- \\
2.49\end{array}$ & 0.98 \\
\hline $\mathrm{T} 1-2$ & $\begin{array}{l}36 \\
(40.0 \%)\end{array}$ & $\begin{array}{l}54 \\
(60.0 \%)\end{array}$ & & & & & & \\
\hline T3-4 & $\begin{array}{l}31 \\
(33.3 \%)\end{array}$ & $\begin{array}{l}62 \\
(66.7 \%)\end{array}$ & & & & & & \\
\hline \multicolumn{3}{|l|}{ Clinical N stage } & 1.09 & $\begin{array}{l}0.59- \\
2.04\end{array}$ & 0.78 & 0.83 & $\begin{array}{l}0.36- \\
1.91\end{array}$ & 0.66 \\
\hline NO & $\begin{array}{l}43 \\
(37.4 \%)\end{array}$ & $\begin{array}{l}72 \\
(62.6 \%)\end{array}$ & & & & & & \\
\hline $\mathrm{N} 1-2$ & $\begin{array}{l}24 \\
(35.3 \%)\end{array}$ & $\begin{array}{l}44 \\
(64.7 \%)\end{array}$ & & & & & & \\
\hline \multicolumn{9}{|c|}{ Values are expressed as the number (percentage) or median value (range). } \\
\hline \multicolumn{9}{|c|}{$\begin{array}{l}\text { ISR: intersphincteric resection, LAR: low anterior resection, LS: laparoscopic surgery, RS: robotic- } \\
\text { assisted surgery, Cl: confidence interval, BMI: body mass index, AV: anal verge }\end{array}$} \\
\hline
\end{tabular}




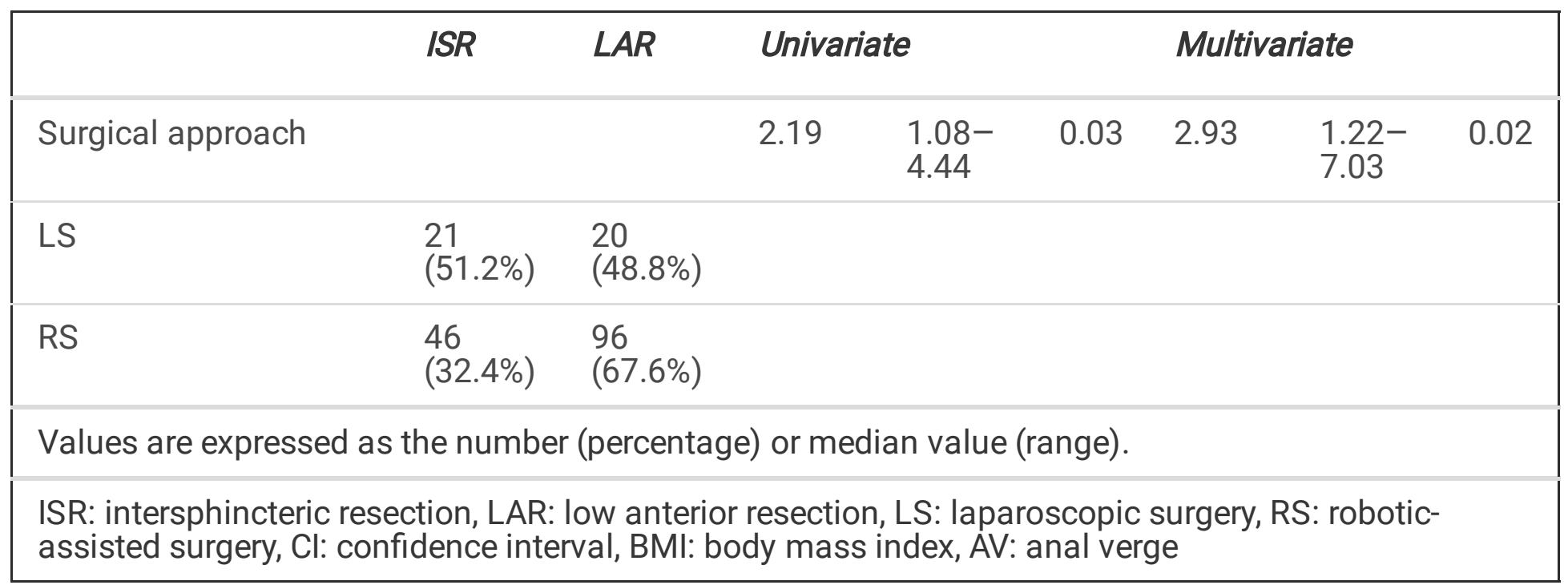

Table 4 summarizes the postoperative complications. The rate of postoperative complications ( $\geq$ Clavien-Dindo grade II) was similar between the groups. Postoperative mortality did not occur in either group.

Table 4

Postoperative complications

\begin{tabular}{|c|c|c|c|}
\hline & $L S$ & $R S$ & \\
\hline & $(n=41)$ & $(n=142)$ & $p$ \\
\hline$\geq$ Grade $\otimes$ (Clavien-Dindo) & $11(26.8 \%)$ & 35 (24.6\%) & 0.84 \\
\hline Ileus & $3(7.3 \%)$ & $4(2.8 \%)$ & 0.19 \\
\hline Anastomotic leakage & $2(4.9 \%)$ & $8(5.6 \%)$ & 1.00 \\
\hline Enteritis & $2(4.9 \%)$ & $2(1.4 \%)$ & 0.22 \\
\hline Urinary tract infection & $1(2.4 \%)$ & $7(4.9 \%)$ & 0.69 \\
\hline Urinary retention & $1(2.4 \%)$ & $6(4.2 \%)$ & 1.00 \\
\hline Wound infection & $1(2.4 \%)$ & $3(2.1 \%)$ & 1.00 \\
\hline Pneumonia & $1(2.4 \%)$ & $2(1.4 \%)$ & 0.54 \\
\hline Abdominal abscess & $1(2.4 \%)$ & $1(0.7 \%)$ & 0.40 \\
\hline Intra-abdominal bleeding & $0(0.0 \%)$ & $3(2.1 \%)$ & 1.00 \\
\hline Others & $1(2.4 \%)$ & $3(2.1 \%)$ & 1.00 \\
\hline Mortality & $0(0.0 \%)$ & $0(0.0 \%)$ & 1.00 \\
\hline \multicolumn{4}{|c|}{ Values are expressed as the number (percentage) or median value (range) } \\
\hline \multicolumn{4}{|c|}{ LS: laparoscopic surgery, RS: robotic-assisted surgery } \\
\hline
\end{tabular}


Table 5 shows the pathological results. Complete local resection (R0) rates and distal resection margins were similar between the LS and RS groups.

Table 5

Pathological outcomes

\begin{tabular}{|c|c|c|c|}
\hline & $L S$ & $R S$ & \\
\hline & $(n=41)$ & $(n=142)$ & $p$ \\
\hline Pathological T stage & & & 0.34 \\
\hline T1 & $16(39.0 \%)$ & $43(30.3 \%)$ & \\
\hline $\mathrm{T} 2$ & $15(36.6 \%)$ & $45(31.7 \%)$ & \\
\hline T3 & $8(19.5 \%)$ & $48(38.8 \%)$ & \\
\hline T4 & $2(4.9 \%)$ & $6(4.2 \%)$ & \\
\hline Pathological N stage & & & 0.86 \\
\hline NO & $28(68.3 \%)$ & $97(68.3 \%)$ & \\
\hline N1 & $9(22.0 \%)$ & $27(19.0 \%)$ & \\
\hline N2 & $4(9.8 \%)$ & $18(12.7 \%)$ & \\
\hline Pathological stage & & & 0.15 \\
\hline I & $25(61.0 \%)$ & $73(51.4 \%)$ & \\
\hline II & $2(4.9 \%)$ & $25(17.6 \%)$ & \\
\hline III & $13(31.7 \%)$ & $36(25.4 \%)$ & \\
\hline IV & $1(2.4 \%)$ & $8(5.6 \%)$ & \\
\hline Local resection margin & & & 1.00 \\
\hline Ro & $41(100 \%)$ & $140(98.6 \%)$ & \\
\hline R1 & $0(0.0 \%)$ & $2(1.4 \%)$ & \\
\hline R2 & $0(0.0 \%)$ & $0(0.0 \%)$ & \\
\hline \multirow[t]{2}{*}{ Distal resection margin $(\mathrm{mm})$} & 14.5 & 16.0 & 0.60 \\
\hline & $(0.5-35.0)$ & $(0.5-50.0)$ & \\
\hline \multicolumn{4}{|c|}{ Values are expressed as the number (percentage) or median value (range). } \\
\hline LS: laparoscopic surgery, RS: & $\mathrm{c}$-assisted $\mathrm{s}$ & & \\
\hline
\end{tabular}

\section{Discussion}


In this study, we evaluated whether RS has technical superiority over LS for ultra-low rectal cancer by comparing LAR frequency in patients who underwent SPOs. Compared to LS, RS was significantly associated with an increased frequency of LAR in SPOs for ultra-low rectal cancer. Our findings support the argument that RS has technical superiority over LS for ultra-low rectal cancer treatment.

Minimally invasive surgery for low rectal cancer requires highly advanced surgical skills. The lower the tumor is located in the deep and narrow pelvis, the more technically challenging the procedure becomes. Previously, APR was the standard procedure for low rectal cancers within $5 \mathrm{~cm}$ of the AV $[16,26,27]$. However, ISR is now widely recognized as an acceptable SPO procedure [28]. Moreover, recent advances in surgical techniques have made it possible to perform LAR, including partial excision of the internal anal sphincter, via a transabdominal approach for ultra-low rectal cancer $[17,29]$.

That said, LAR for ultra-low rectal cancer requires mobilization of the rectum, even in the anal canal, by the transabdominal approach, which still requires highly advanced surgical techniques. Therefore, the technical superiority of RS over LS could be evaluated by comparing the frequency of LAR between these two types of SPOs for ultra-low rectal cancer. To the best of our knowledge, no previous study has attempted to compare the types of SPOs between LS and RS for ultra-low rectal cancer. In contrast to previous reports, we excluded APR, the indications of which are determined by the tumor and technical and non-technical factors, such as preoperative anorectal dysfunction and tolerance of postoperative defecatory dysfunction. As such, the types of SPOs utilized for the patients herein were determined largely based on technical factors, which is also a strong point of our study.

In this study, LAR frequency was significantly higher in the RS group (67.6\%) than in the LS group (48.8\%), and multivariate analyses showed that RS and the tumor distance from the AV were significantly associated with an increased frequency of LAR for ultra-low rectal cancer. Furthermore, there were no significant differences in the postoperative complications or the pathological results between the RS and LS groups. Although the operation time was longer in the RS group, this was attributed to the higher proportion of patients who underwent LLD in the RS group. Hence, compared to LS, RS allows transection of the distal rectum for ultra-low rectal cancer via the transabdominal approach, without compromising surgical and pathological outcomes. These findings suggest that RS has technical superiority over LS for ultra-low rectal cancer. This superiority can be attributed to the technology involved in RS, such as digital suppression of hand tremors, free-moving multi-joint forceps, and high-quality three-dimensional visualization. Furthermore, the robotic stapler may be advantageous during stapling owing to its good maneuverability $[30,31]$.

In addition to the transabdominal approach, TaTME has been used for rectal cancer [32]. It has been reported that the transanal approach could enhance access to the distal part of the rectum and enable better visualization making a more accurate oncological dissection possible [33, 34]. However, early adopters of TaTME underscored its technical difficulty. Several studies examining TaTME registry data have revealed that patients sustained visceral injuries during perineal dissection [35, 36]. Additionally, Wasmuth et al [37]. demonstrated that the oncological outcomes after TaTME were inferior to the 
national results. Further investigation is required to evaluate the long-term oncological results of TaTME. In contrast, RS makes it possible to perform surgery safely and precisely, even for ultra-low rectal cancer via the transabdominal approach, which is commonly used for TME. Since RS is performed in a familiar transabdominal field-of-view, it is easy to recognize the anatomy and the surgery can be performed safely even in the deep pelvis. Furthermore, several studies have indicated good long-term results $[2,11,38]$.

This study has several limitations. First, this was a retrospective study performed at a single institution. Second, long-term outcomes were not investigated. Randomized controlled trials are necessary to validate our findings. Third, although this study focused on the technical aspects, it was unclear whether LAR or ISR is better in terms of postoperative anorectal function. Previous studies have reported that patients who have undergone ISR have a higher risk of fecal incontinence and bowel dysfunction than those who have undergone $\operatorname{LAR}[39,40]$. However, the characteristics of patients in previous studies were different from those in this study, and these results could not be extrapolated to the present study. Further studies are necessary to clarify the effects on postoperative anal function.

\section{Conclusion}

The findings of the present study revealed that RS significantly increased the frequency of transection of the rectum by the transabdominal approach in SPOs, supporting that RS has technical superiority over LS for the treatment of ultra-low rectal cancer.

\section{Abbreviations}

RS: Robotic-assisted surgery; LS: Laparoscopic surgery; OS: Open surgery; SPOs: Sphincter-preserving operations; APR: Abdominoperineal resection; LAR: Low anterior resection; ISR: Intersphincteric resection; AV: Anal verge; TME: Total mesorectal excision; TaTME: Transabdominal total mesorectal excision; LLD: Lateral lymph node dissection; BMI: Body mass index; ASA-PS: American Society of AnesthesiologistsPhysical Status; Cl: Confidence interval

\section{Declarations}

\section{Ethics approval and consent to participate}

The study was approved by the institutional review board of Shizuoka Cancer Center (Approval Code: J2020-37-2020-1-3) and it conforms to the provisions of the Declaration of Helsinki.

\section{Consent for publication}

Not applicable.

\section{Availability of data and materials}


The datasets used and/or analyzed during the current study are available from the corresponding author on reasonable request.

\section{Competing interests}

The authors declare that they have no competing interests.

\section{Funding}

This manuscript did not receive sponsorship for publication

\section{Authors' contributions}

TK and HH drafted the paper. HH designed this study. AS, HK, YY, SM, MH, and SK obtained and analyzed data. All authors critically revised the report, commented on drafts of the manuscript, and approved the final report.

\section{Acknowledgements}

Not applicable.

\section{References}

1. Prete FP, Pezzolla A, Prete F, Testini M, Marzaioli R, Patriti A, et al. Robotic versus laparoscopic minimally invasive surgery for rectal cancer: A systematic review and meta-analysis of randomized controlled trials. Ann Surg. 2018;267(6):1034-46.

2. Kim J, Baek S-J, Kang D-W, Roh Y-E, Lee J, Kwak H-D, et al. Robotic resection is a good prognostic factor in rectal cancer compared with laparoscopic resection: Long-term survival analysis using propensity score matching. Dis Colon Rectum. 2017;60(3):266-73.

3. Jayne D, Pigazzi A, Marshall H, Croft J, Corrigan N, Copeland J, et al. Effect of Robotic-Assisted vs Conventional Laparoscopic Surgery on Risk of Conversion to Open Laparotomy Among Patients Undergoing Resection for Rectal Cancer: The ROLARR Randomized Clinical Trial. JAMA. 2017;318(16):1569-80.

4. Yamaoka Y, Kagawa H, Shiomi A, Yamakawa Y, Hino H, Manabe S, et al. Robotic-assisted surgery may be a useful approach to protect urinary function in the modern era of diverse surgical approaches for rectal cancer. Surg Endosc. 2021;35(3):1317-23.

5. Chang W, Wei Y, Ren L, Jian M, Chen Y, Chen J, et al. Short-term and long-term outcomes of robotic rectal surgery-from the real word data of 1145 consecutive cases in China. Surg Endosc. 2020;34(9):4079-88.

6. Yamaguchi T, Kinugasa Y, Shiomi A, Kagawa H, Yamakawa Y, Furutani A, et al. Oncological outcomes of robotic-assisted laparoscopic versus open lateral lymph node dissection for locally advanced low rectal cancer. Surg Endosc. 2018;32(11):4498-505. 
7. Shiomi A, Kinugasa Y, Yamaguchi T, Kagawa H, Yamakawa Y. Robot-assisted versus laparoscopic surgery for lower rectal cancer: the impact of visceral obesity on surgical outcomes. Int $\mathrm{J}$ Color Dis. 2016;31(10):1701-10.

8. D'Annibale A, Pernazza G, Monsellato I, Pende V, Lucandri G, Mazzocchi P, et al. Total mesorectal excision: a comparison of oncological and functional outcomes between robotic and laparoscopic surgery for rectal cancer. Surg Endosc. 2013;27(6):1887-95.

9. Baik SH, Kwon HY, Kim JS, Hur H, Sohn SK, Cho CH, et al. Robotic versus laparoscopic low anterior resection of rectal cancer: short-term outcome of a prospective comparative study. Ann Surg Oncol. 2009;16(6):1480-7.

10. Colombo PE, Bertrand MM, Alline M, Boulay E, Mourregot A, Carrere S, et al. Robotic Versus Laparoscopic Total Mesorectal Excision (TME) for Sphincter-Saving Surgery: Is There Any Difference in the Transanal TME Rectal Approach?: A Single-Center Series of 120 Consecutive Patients. Ann Surg Oncol. 2016;23(5):1594-600.

11. Kang J, Yoon KJ, Min BS, Hur H, Baik SH, Kim NK, et al. The impact of robotic surgery for mid and low rectal cancer: a case-matched analysis of a 3-arm comparison-open, laparoscopic, and robotic surgery. Ann Surg. 2013;257(1):95-101.

12. Hashiguchi Y, Muro K, Saito Y, Ito Y, Ajioka Y, Hamaguchi T, et al. Japanese Society for Cancer of the Colon and Rectum (JSCCR) guidelines 2019 for the treatment of colorectal cancer. Int J Color Dis. 2020;25(1):1-42.

13. Ito M, Saito N, Sugito M, Kobayashi A, Nishizawa Y, Tsunoda Y. Analysis of Clinical Factors Associated with Anal Function after Intersphincteric Resection for Very Low Rectal Cancer. Dis Colon Rectum. 2009;52(1):64-70.

14. Heald RJ, Husband EM, Ryall RD. The mesorectum in rectal cancer surgery-the clue to pelvic recurrence? Br J Surg. 1982;69(10):613-6.

15. Japanese Society for Cancer of the C, Rectum. Japanese Classification of Colorectal, Appendiceal, and Anal Carcinoma: the 3d English Edition [Secondary Publication]. Journal of the Anus Rectum Colon. 2019;3(4):175-95.

16. Saito N, Moriya Y, Shirouzu K, Maeda K, Mochizuki H, Koda K, et al. Intersphincteric resection in patients with very low rectal cancer: a review of the Japanese experience. Dis Colon Rectum. 2006;49(Suppl 10):13-22.

17. Kim JC, Lim SB, Yoon YS, Park IJ, Kim CW, Kim CN. Completely abdominal intersphincteric resection for lower rectal cancer: feasibility and comparison of robot-assisted and open surgery. Surg Endosc. 2014;28(9):2734-44.

18. Brierley JD, Gospodarowicz MK, Wittekind C. TNM classification of malignant tumours. 8th ed. New Jersey: edn. Wiley-Blackwell; 2017.

19. Yamaguchi T, Kinugasa Y, Shiomi A, Tomioka H, Kagawa H. Robotic-assisted laparoscopic versus open lateral lymph node dissection for advanced lower rectal cancer. Surg Endosc. 2016;30(2):7218. 
20. Kagawa H, Kinugasa Y, Shiomi A, Yamaguchi T, Tsukamoto S, Tomioka H, et al. Robotic-assisted lateral lymph node dissection for lower rectal cancer: short-term outcomes in 50 consecutive patients. Surg Endosc. 2015;29(4):995-1000.

21. Akiyoshi T, Watanabe T, Miyata S, Kotake K, Muto T, Sugihara K, et al. Results of a Japanese nationwide multi-institutional study on lateral pelvic lymph node metastasis in low rectal cancer: is it regional or distant disease? Ann Surg. 2012;255(6):1129-34.

22. Yamaguchi T, Kinugasa Y, Shiomi A, Tomioka H, Kagawa H, Yamakawa Y. Robotic-assisted vs. conventional laparoscopic surgery for rectal cancer: short-term outcomes at a single center. Surg Today. 2016;46(8):957-62.

23. Shiomi A, Kinugasa Y, Yamaguchi T, Tsukamoto S, Tomioka H, Kagawa H. Feasibility of laparoscopic intersphincteric resection for patients with cT1-T2 low rectal cancer. Dig Surg. 2013;30(4-6):272-7.

24. Shiomi A, Kinugasa Y, Yamaguchi T, Tomioka H, Kagawa H. Robot-assisted rectal cancer surgery: short-term outcomes for 113 consecutive patients. Int J Color Dis. 2014;29(9):1105-11.

25. Dindo D, Demartines N, Clavien P-A. Classification of surgical complications: a new proposal with evaluation in a cohort of 6336 patients and results of a survey. Ann Surg. 2004;240(2):205-13.

26. Tsukamoto S, Kanemitsu Y, Shida D, Ochiai H, Mazaki J. Comparison of the clinical results of abdominoperanal intersphincteric resection and abdominoperineal resection for lower rectal cancer. Int J Color Dis. 2017;32(5):683-9.

27. Rullier E, Laurent C, Bretagnol F, Rullier A, Vendrely V, Zerbib F. Sphincter-saving resection for all rectal carcinomas: the end of the 2-cm distal rule. Ann Surg. 2005;241(3):465-9.

28. Schiessel R, Karner-Hanusch J, Herbst F, Teleky B, Wunderlich M. Intersphincteric resection for low rectal tumours. Br J Surg. 1994;81(9):1376-8.

29. Kim JC, Lee JL, Bong JW, Seo JH, Kim CW, Park SH, et al. Oncological and anorectal functional outcomes of robot-assisted intersphincteric resection in lower rectal cancer, particularly the extent of sphincter resection and sphincter saving. Surg Endosc. 2020;34(5):2082-94.

30. Tejedor P, Sagias F, Nock D, Flashman K, Naqvi S, Kandala NL, et al. Advantages of using a robotic stapler in rectal cancer surgery. J Robot Surg. 2020;14(2):365-70.

31. Johnson CS, Kassir A, Marx DS, Soliman MK. Performance of da Vinci Stapler during roboticassisted right colectomy with intracorporeal anastomosis. J Robot Surg. 2019;13(1):115-9.

32. Sylla P, Rattner DW, Delgado S, Lacy AM. NOTES transanal rectal cancer resection using transanal endoscopic microsurgery and laparoscopic assistance. Surg Endosc. 2010;24(5):1205-10.

33. Roodbeen SX, de Lacy FB, van Dieren S, Penna M, Ris F, Moran B, et al. Predictive Factors and Risk Model for Positive Circumferential Resection Margin Rate After Transanal Total Mesorectal Excision in 2653 Patients With Rectal Cancer. Ann Surg. 2019;270(5):884-91.

34. European Society of Coloproctology collaborating g. An international multicentre prospective audit of elective rectal cancer surgery; operative approach versus outcome, including transanal total mesorectal excision (TaTME). Colorectal Dis. 2018;20(Suppl 6):33-46. 
35. Penna M, Hompes R, Arnold S, Wynn G, Austin R, Warusavitarne J, et al. Transanal Total Mesorectal Excision: International Registry Results of the First 720 Cases. Ann Surg. 2017;266(1):111-7.

36. Deijen CL, Tsai A, Koedam TW, Veltcamp Helbach M, Sietses C, Lacy AM, et al. Clinical outcomes and case volume effect of transanal total mesorectal excision for rectal cancer: a systematic review. Tech Coloproctol. 2016;20(12):811-24.

37. Wasmuth HH, Faerden AE, Myklebust TA, Pfeffer F, Norderval S, Riis R, et al. Transanal total mesorectal excision for rectal cancer has been suspended in Norway. Br J Surg. 2020;107(1):12130.

38. Yamaguchi T, Kinugasa $Y$, Shiomi A, Kagawa H, Yamakawa $Y$, Furuatni A, et al. Short- and long-term outcomes of robotic-assisted laparoscopic surgery for rectal cancer: results of a single high-volume center in Japan. Int J Color Dis. 2018;33(12):1755-62.

39. Bretagnol F, Rullier E, Laurent C, Zerbib F, Gontier R, Saric J. Comparison of functional results and quality of life between intersphincteric resection and conventional coloanal anastomosis for low rectal cancer. Dis Colon Rectum. 2004;47(6):832-8.

40. Denost Q, Moreau JB, Vendrely V, Celerier B, Rullier A, Assenat V, et al. Intersphincteric resection for low rectal cancer: the risk is functional rather than oncological. A 25-year experience from Bordeaux. Colorectal Dis. 2020.

\section{Figures}




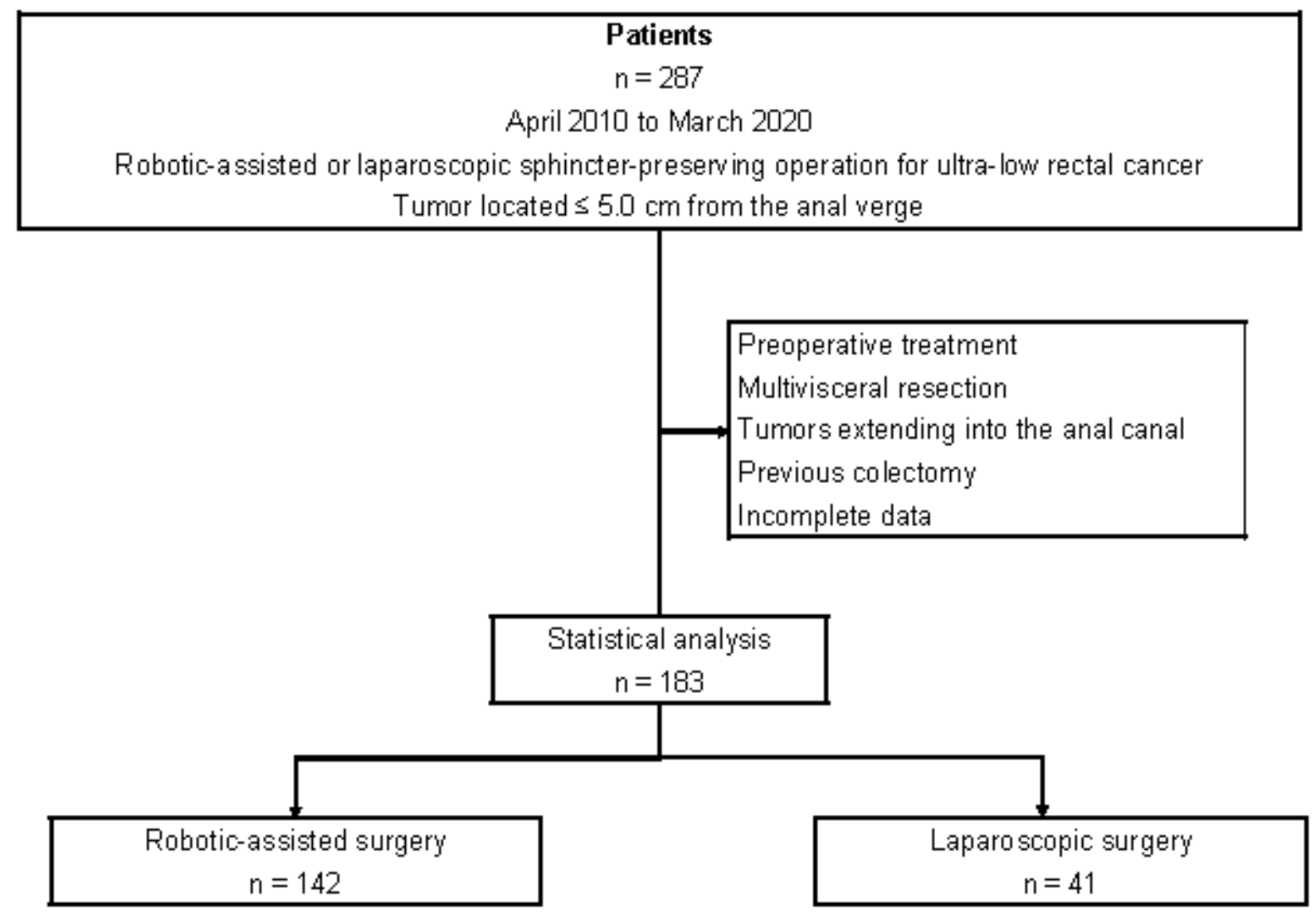

Figure 1

Flowchart of patient selection

\section{Supplementary Files}

This is a list of supplementary files associated with this preprint. Click to download.

- supplementarytable1.docx 